\title{
Probiotics and Oral Malodor
}

\author{
Nitish Bhat ${ }^{1}$, Nandini Bhardwaj ${ }^{2}$, Abhiney Puri ${ }^{3}$, Rajat Nangia ${ }^{4}$
}

\begin{abstract}
The efficacy of probiotics or the viable bacteria specifically in the oral cavity with proven health benefits acts as a natural approach against the naturally developing microbiome imbalance and is enormously popular worldwide. To put a stop to oral diseases, probiotics bring to us an imperative concept of biological changes in microbial flora. Various clinical studies reveal the reduction in the concentration of bacteria causing dental caries, halitosis, and periodontitis. The prevention and control of oral malodor or halitosis is spotlighted as it unswervingly affects the communal life in polygenic unfavorable ways. This paper evaluates the present acquaintance, etiology, verdict, and promising management approaches for oral malodor with probiotics.
\end{abstract}

Keywords: Bacterial strains, Colonization, Oral malodor, Probiotics, Volatile sulfur compounds.

Journal of Health Sciences \& Research (2019): 10.5005/jp-journals-10042-1078

\section{INTRODUCTION}

Genetics, diet, stress, and disease influence the emission of variety of volatile and nonvolatile molecules by humans. A complaint analogous to body odor ${ }^{1}$ called oral malodor, also called halitosis or bad breath (fetor ex ore) ${ }^{2}$ describes any disagreeable odor in the breath. ${ }^{1}$ The oral odors include ozostomia, stomatodysodia, halitosis, and fetor oris/ex ore. ${ }^{3}$ According to Tonzetich, ${ }^{4}$ bad breaths prevails as a severe chronic problem in about $50 \%$ of population. Personal discomfort along with social embarrassment signals its consequence as presence of disease leading to emotional distress. $^{2}$

\section{Oral Malodor}

Various terminologies used the following: halitosis, bad breadth, fetor ex ore. ${ }^{2}$ Definition: bad or unpleasant smells from the oral cavity or outside the oral cavity. ${ }^{4}$ Latin meaning: "Halitus," breath and "Osis," pathological process in Greek. ${ }^{4}$

Gram negative anaerobes present on the dorsum of the tongue and some residing in periodontal pockets mainly contributes to ascription of bad breath in the oral cavity. ${ }^{1}$ Bacterial putrefaction results in some chemical end products known as volatile sulfur compounds (VSCs). Cysteine, cystine, and methionine are the sulfur amino acids on which bacteria act and produce offensive odor 20 and compounds like VSCs such as hydrogen sulfide $\left(\mathrm{H}_{2} \mathrm{~S}\right)$, methyl mercaptan $\left(\mathrm{CH}_{3} \mathrm{SH}\right)$, and dimethyl sulfide $\left(\mathrm{CH}_{3} \mathrm{SCH}_{3}\right)$ as metabolites. ${ }^{5}$ Implications of some nonsulfur containing compounds such as cadaverine, putrescine, indole, and skatole have also been found. ${ }^{6}$

A disease with several disorders including metabolic, respiratory ${ }^{7}$ consumption of foods like spices, garlic, and consumption of alcohol and tobacco chewing $60^{1}$ needs to be improved. It has been shown that the use of probiotics in, the suppression of oral malodor serves as an adjunct for its prevention and treatment. ${ }^{2}$ According to United Nation's Food and Agricultural Organization (FAO) and the World Health Organization (WHO): defined probiotics as living microorganisms, principally bacteria that are safe for human consumption, and when ingested in sufficient quantities, it has beneficial effects on human health, beyond basic nutrition. ${ }^{8}$

Colonization of probiotics bacterial strains, i.e., bacteriotherapy improves this condition by replacement of bacteria in halitosis with
${ }^{1}$ Department of Oral Pathology, Indira Gandhi Government Dental College, Amphalla, Jammu and Kashmir, India

${ }^{2-4}$ Department of Oral and Maxillofacial Pathology, Microbiology and Forensic Odontology, Himachal Institute of Dental Sciences, Sirmour, Himachal Pradesh, India

Corresponding Author: Nandini Bhardwaj, Department of Oral and Maxillofacial Pathology, Microbiology and Forensic Odontology, Himachal Institute of Dental Sciences, Sirmour, Himachal Pradesh, India, Phone: +91 9816173522, e-mail: nandinibhardwaj313@gmail. com

How to cite this article: Bhat N, Bhardwaj N, Puri A, et al. Probiotics and Oral Malodor. J Health Sci Res 2019;10(2):31-34.

Source of support: Nil

Conflict of interest: None

the colonization of probiotics bacterial strains from humans, i.e., bacteriotherapy improves this condition. ${ }^{1}$

\section{Discussion}

Halitosis proves to be among the 100 most common causes of distress with $50 \%$ prevalence according to a study in The Netherlands. ${ }^{4}$ Many etiological factors contribute to the attribution of bad breath from the oral cavity including local and systemic disorders. ${ }^{2}$ Solobacterium moorei is the bacterium associated with halitosis, but in some cases of halitosis, specific bacterial species are associated with peptides such as glutathione, proteins, and salivary mucins. ${ }^{9}$ Etiological compartment of oral malodor can be grouped into intrinsic/intraoral sources and extrinsic/extraoral sources. Poor oral hygiene, plaque-related gingival and periodontal diseases such as gingivitis, periodontitis, and systemic diseases such as infectious, cutaneous, gastrointestinal diseases, and reduced salivary flow, etc., are the factors predisposing to intraoral or intrinsic halitosis (Table 1). ${ }^{1,10,11}$

Oral factors contribute to $90 \%$ along with $10 \%$ systemic factors. ${ }^{2}$ Conditions which do not affect the oral cavity primarily, i.e., extraoral causes seem to be in less association with halitosis. ${ }^{1}$ Extraoral sources include polyps, postnasal drips, sinusitis, and in women during ovulation, menopause, etc. Bronchial and lung

o The Author(s). 2019 Open Access This article is distributed under the terms of the Creative Commons Attribution 4.0 International License (https://creativecommons. org/licenses/by-nc/4.0/), which permits unrestricted use, distribution, and non-commercial reproduction in any medium, provided you give appropriate credit to the original author(s) and the source, provide a link to the Creative Commons license, and indicate if changes were made. The Creative Commons Public Domain Dedication waiver (http://creativecommons.org/publicdomain/zero/1.0/) applies to the data made available in this article, unless otherwise stated. 
infections along with biochemical disorders can also contribute to bad breath. ${ }^{2}$ Microbial etiology of halitosis can also be explained on the basis of two theories. First being the specific theory which states that only few specific single species causes malodor. Nonspecific theory works on the principle of biotransformation of substrates into volatile compounds by many bacterial species mostly anaerobes. ${ }^{1}$ Halitosis is grouped into delusional (pseudohalitosis and halitophobia) and genuine halitosis. Genuine halitosis is further divided into physiologic and pathologic as explained in Table 2.

Pathologic halitosis with extraoral causes associated with various systems and their causative agent is explained in Table $3^{4}$ extraoral halitosis.

Table 1: Indicates the list of probiotic strains effective against the production of volatile sulfur compound causing halitosis

\begin{tabular}{|c|c|c|}
\hline Author/year & Study design & Method effectiveness \\
\hline Burton et al., $2006^{30}$ & $\begin{array}{l}\text { Strain used- } \\
\text { S. salivarius K12; } \\
\text { Lozenges containing } \\
\text { S. salivarius strain } \\
\text { along with } 3 \text { days } \\
\text { chlorhexidine mouth } \\
\text { wash rinsing }\end{array}$ & $\begin{array}{l}\text { Reduction in } \\
\text { number of VSC by } \\
\text { bacteriocin producing } \\
\text { S. salivarius given after } \\
\text { mouth wash }\end{array}$ \\
\hline \multirow[t]{3}{*}{$\begin{array}{l}\text { Iwamoto et al., } \\
2010^{27}\end{array}$} & \multirow{3}{*}{$\begin{array}{l}\text { Strain used- } \\
(1) \text { L. salivarius } \\
\text { WB21 }\left(2.01 \times 10^{9}\right) \text {; } \\
\text { dissolution in mouth } \\
\text { daily along with } \\
840 \mathrm{mg} \text { of xylitolol } \\
\text { tablets; }(2) \text { L. reuteri } \\
\text { in the form of straw } \\
\text { or tablet }\end{array}$} & $\begin{array}{l}\text { Control of malodor } \\
\text { and malodor-related } \\
\text { factors }^{31}\end{array}$ \\
\hline & & $\begin{array}{l}\text { Improved } \\
\text { physiological halitosis }\end{array}$ \\
\hline & & $\begin{array}{l}\text { Reduction of S. mutans } \\
\text { levels }^{32}\end{array}$ \\
\hline \multirow[t]{2}{*}{ Kang et al., $2006^{33}$} & \multirow[t]{2}{*}{$\begin{array}{l}\text { Strain used- } \\
\text { W. ciberia }\end{array}$} & $\begin{array}{l}\text { Inhibition of } \\
\text { production of VSC } \\
\text { by F. nucleatum }\end{array}$ \\
\hline & & $\begin{array}{l}\text { Reduced production of } \\
\mathrm{H}_{2} \mathrm{~S}, \mathrm{CH}_{2} \mathrm{SH}\end{array}$ \\
\hline
\end{tabular}

Table 2: Genuine halitosis which is being further divided into physiologic and pathologic halitosis

\begin{tabular}{|c|c|}
\hline Delusional halitosis & Pseudohalitosis and halitophobia \\
\hline Pseudohalitosis & $\begin{array}{l}\text { Objectively undiagnosed halitosis } \\
\text { where the patient's oral malodor is } \\
\text { not felt by others but his/her chief } \\
\text { complaint is halitosis }\end{array}$ \\
\hline Halitophobia & $\begin{array}{l}\text { Patient declares his breath as } \\
\text { bad smell fearing about having a } \\
\text { continuous oral malodor in spite of } \\
\text { the treatment }{ }^{4}\end{array}$ \\
\hline Genuine halitosis & Two types: \\
\hline \multirow{2}{*}{$\begin{array}{l}\text { where breath malodor can } \\
\text { be verified objectively }\end{array}$} & Physiologic halitosis \\
\hline & Pathologic halitosis \\
\hline \multirow[t]{2}{*}{ Physiologic halitosis } & Also termed as transient halitosis \\
\hline & E.g., morning breath \\
\hline \multirow[t]{2}{*}{ Pathologic halitosis } & Subclassified into \\
\hline & $\begin{array}{l}\text { - Oral malodor (fetor oris fetor } \\
\text { ex oris) and } \\
\text { - } \text { Extraoral }^{1}\end{array}$ \\
\hline
\end{tabular}

Table 3: Pathologic halitosis with extraoral causes associated with various systems and their causative agent

\begin{tabular}{ll}
\hline System & Causative agent \\
\hline $\begin{array}{l}\text { Halitosis originating from respiratory } \\
\text { system }\end{array}$ & Pseudomonas aeruginosa ${ }^{12}$ \\
Halitosis originating from & Enterococcus faecalis $^{12}$ \\
gastrointestinal system & Helicobacter pylori $^{12}$ \\
& P. gingivalis \\
& T. denticola \\
& T. forsythia \\
& Cystinosis $^{4}$ \\
Halitosis originating from metabolic & Hypernatremia \\
diseases & Trimethylaminuria \\
& Acetaminophen \\
Halitosis originating from drugs & Chloral hydrate \\
& Disulfiram \\
\end{tabular}

The severity of oral malodor can be increased by periodontitis, ${ }^{13,14}$ deep periodontal pockets promoting the growth of gram negative bacteria Treponema denticola (T. denticola), Porphyromonas gingivalis (P. gingivalis), T. forsythensis, and Fusobacterium nucleatum (F. nucleatum) ${ }^{14,15}$ which form VSCs. diagnosis of oral malodor can be done by a variety of tests including direct and indirect methods. The tests include spoon test (assessing malodor from the dorsum of the tongue), dental floss odor test (interdental plaque odor assessment), and saliva odor test, etc. ${ }^{2}$

This multifactorial problem requires a well-defined approach for diagnosis and treatment. The cause of bad breath, i.e., due to oral causes or not, should be recorded in the halitosis history along with thorough medical and dental history. ${ }^{2}$ Its management depends on the cause. The components which are hazardous and sensible to cause halitosis should be avoided including smoking, foods, and drugs. Unfavorable odor can be masked by nonpharmacological methods including mints, gums, mouth rinses, and sprays, etc. ${ }^{11}$

Various chemical and mechanical methods reduce the volatile compound formation and therefore reduce the overgrowth of microbes causing halitosis. ${ }^{2,16}$ Treatment of oral diseases and improving oral hygiene also contributes to its prevention. ${ }^{1}$

Suppression of oral malodor by probiotics by implication of indigenous oral microflora, ${ }^{2}$ i.e., bacteriotherapy from healthy humans serves as an adjunct in the treatment of halitosis. ${ }^{1}$

The term probiotics was initially proposed by Lilley and Stillwell in 1965. Fuller (1989) defined them as 'A live microbial food supplement, which beneficially affects the host animal by improving its microbial balance. ${ }^{17}$ These are the microbes which have a distinct viability when given in sufficient doses provides various health benefits. ${ }^{18}$ Different probiotics bacterial strains include Aerococcus, Enterococcus, Lactobacillus, Lactococcus, Leuconostoc, Oenococcus, Pediococcus, Streptococcus, Carnobacterium, Tetragenococcus, Vagococcus, and Weissella genera and are grouped into LAB, i.e., probiotic lactic acid bacteria. ${ }^{7}$ Lactobacillus and Bifidobacterium are the most commonly used probiotic strains. B. Bifidum, B. dentium, and $B$. longum are the species belonging to Bifidobacterium which are isolated from oral cavity and are used as a probiotic strain that forms the prevention and treatment of various oral diseases. L. paracasei, L. plantarum, L. rhamnosus, and L. salivarius. ${ }^{7-10}$ are the species belonging to Lactobacillus probiotic strain. ${ }^{19-22}$ Saccharomyces boulardii is the only yeast used as a probiotic strain. ${ }^{17}$ 
Probiotic strains belonging to Lactobacillus, Bifidobacterium, Enterococcus, and Streptococcus genera are used in synbiotic associations. ${ }^{23}$ An ideal probiotic should be nontoxic with high cell viability and nonpathogenic. ${ }^{17}$ Different local and systemic mechanisms are involved in the action of probiotics. Different probiotics have different actions according to disease phase in which it is administered. ${ }^{24}$ The basic mechanism involved is decreasing the vitality and growth of pathogen by occupying a niche that is colonized by pathogens and by adversely affecting the growth of that pathogen. It results in limiting the adherence of the pathogen to epithelial surface by modulating the epithelial permeability. ${ }^{17}$ Mode of action of probiotics in oral cavity is explained by its adhesion to the oral surface. The adhesion mechanism is explained on the basis of two model systems containing proteins and buffers in saliva-coated hydroxyapatite. ${ }^{23}$ It is not possible to provide all the health benefits by a single probiotic strain, and specific health conditions are improved by specific strains. Probiotics generally leads to the improvement of lactose digestion, blood cholesterol, and controls intestinal $\mathrm{pH} 27 \times 10^{6}-10^{7} / \mathrm{kg} / \mathrm{mL}$ that should be present in food to provide health benefits. ${ }^{25,26}$

Probiotic emerges as a cardinal tool and serves as a replacement to antibiotics in solving diseases like dental caries, periodontal diseases, and halitosis. Direct interaction, indirect interaction, and competitive exclusion agility explain the possible mechanism of probiotics in the treatment of these diseases in the oral cavity. Direct interaction results in inhibition of pathogen adhesion, colonization, and biofilm formation. Release of chemicals like hydrogen peroxide, Bacteriocins which results from competing with colonizing bacteria, explains the concept of competitive exclusion agility. Indirect actions constitute apoptosis by cytokines and effect on defense mechanisms, etc. ${ }^{17}$

The holistic approach and treatment plan for halitosis is accompanied by appropriate diagnosis based on the patient history. ${ }^{5}$ Management of both mouth-related and gut-related halitosis can be achieved by probiotics. ${ }^{27}$ Efficacious probiotics strains or bacteriocin producing microorganisms are considered to be effective agents against halitosis. Probiotics strains to limit the growth of bacteria causing halitosis includes Streptococcus salivarius K12, Lactobacillus salivarius WB2, ${ }^{5}$ E. coli Nisle 1917, and Weissella confusa isolates. ${ }^{27}$ Halitosis or oral malodor occurs due to the production of VSCs $\left(\mathrm{H}_{2} \mathrm{~S}\right.$ and $\left.\mathrm{CH}_{4} \mathrm{~S}\right)$ from the amino acids which occurs due to degradation of proteins from the gram negative anaerobic bacteria including ${ }^{7}$ F. nucleatum, P. gingivalis, Prevotella intermedia, and T. denticola.

The VSCs constitute $\mathrm{H}_{2} \mathrm{~S}$ from cysteine produced by Peptostreptococcus, Bacteroides, Selenomas bacterial species, and $\mathrm{CH}_{2} \mathrm{SH}$ from methionine produced by $P$. gingivalis, $P$. intermedia, and $T$. denticola bacteria resulting in halitosis. ${ }^{28}$

Species associated with halitosis include Atopobium parvulum, Eubacterium sulci, Fusobacterium periodontium, Solobacterium moorei, and Streptococcus. ${ }^{29}$

Probiotic strains used as an adjunct to halitosis require the bacteria from the same ecosystem (Colodner et al., 2003; Reid et al., 2003). Strict scientific criteria along with phenotypic profile in controlled clinical trials are a necessity to probiotics bacteria. Oral malodor most commonly originates from the anaerobic bacteria residing in the dorsum of tongue. Major contribution to halitosis is marked by proteolytic microbes producing bacteriocin and adhering to the adhesive molecules on the cell surface of the tongue (Reid and Burton, 2002), De Boever, and Loesche (1995) by degrading host proteins. Reduced production of by-products that produce odor and effective colonization is the perquisites for a probiotics strain for treating halitosis. ${ }^{30}$

\section{Conclusion}

Probiotics emerging as a new area of research in the prevention and treatment of halitosis is gaining momentum with time. Probiotic strains antagonizing the production of VSC producing bacteria causing halitosis and providing oral benefits define its potential in the future. Long-term studies are required to increase its affinity and to discover more probiotics strains preventing oral malodor.

\section{References}

1. Scully C, Greenman J. Halitosis (bad breath). Periodontology 2000 2008;48:67-75. DOI: 10.1111/j.1600-0757.2008.00266.x.

2. Pratibha PK, Bhat KM, Bhat GS. Oral malodor: a review of literature. J Dental Hyg. 2006;80(3):8.

3. Touyz LZ. Oral malodor: a review. J Can Dent Assoc 1993;59(7): 607-610.

4. BicakDA. A current approach to halitosis \& oral malodor-a mini review. open Dent J. 2018;12:322-330. DOI: 10.2174/1874210601812010322.

5. Akaji Ezi A, Folarmani N, Ashiwaju O. Halitosis: a review of literature on its prevalence, impact \& control. Oral Health Prev Dent 2014;12(4): 297-304. DOI: 10.3290/j.ohpd.a33135.

6. Goldberg S, Kozlovsky A, Gordon D, et al. Cadaverine as a putative component of oral malodor. J Dent Res 1994;73(6):1168-1172. DOI: 10.1177/00220345940730060701.

7. Martinez RCR, Bedani R, Saad SMI. Scientific evidence for health effects attributed to the consumption of probiotics \& prebiotics: an update for current perspectives \& future challenges. Br J Nutr 2015;114(12):1993-2015. DOI: 10.1017/S0007114515003864.

8. Zahir S, Bose S, Chaudhury UR. Probiotics and its role in dental caries. Science and Culture 2011;77(11-12):507-510.

9. Sterer N, Bar-Ness Greenstein R, Rosenberg M. $\beta$-Galactosidase activity in saliva is associated with oral malodor. J Dent Res 2002;81(3):182-185. DOI: 10.1177/0810182.

10. Koshimune $S$, Awano S, Gohara K, et al. Low salivary flow and volatile sulfur compounds in mouth air. Oral Surg Oral Med Oral Pathol Oral Radiol Endod 2003;96(1):38-41. DOI: 10.1016/S1079-2104(03)00162-8.

11. Outhouse TL, Al-Alawi R, Fedorowicz Z, et al. Tonguescraping for treating halitosis. Cochrane Database Syst Rev 2006;19(2):CD005519. DOI: 10.1002/14651858.CD005519.pub2.

12. Scully C, Greenman J. Halitology (breath odour: aetiopathogenesis and management). Oral Dis 2012;18(4):333-345. DOI: 10.1111/j.16010825.2011.01890.x.

13. Yaegaki KK, Sanada K. Biochemical and clinical factors influencing oral malodor in periodontal patients. J Periodontol 1992;63(9):783-789. DOI: 10.1902/jop.1992.63.9.783.

14. Goldberg $\mathrm{S}, \mathrm{Cardash} \mathrm{H}$, Browning $\mathrm{H}$, etal. Isolation of Enterobacteriaceae from the mouth and potential association with malodor. J Dent Res 1977;6(11):1770-1775. DOI: 10.1177/00220345970760110801.

15. Yaegaki K, Sanada K. Volatile sulfur compounds in mouth air from clinically healthy subjects and patients with periodontaldisease. J Periodontol Res 1992;27(4 Pt 1):233-238. DOI: 10.1111/j.16000765.1992.tb01673.x.

16. Roldan S, Herrera D, O'Connor A, et al. A combined therapeutic approach to manage oral halitosis: a 3 month prospective case series. J Periodontol 2005;76(6):1025-1033. DOI: 10.1902/jop.2005.76. 6.1025 .

17. Bhat N, Bansal S, Thakur K, et al. Probiotics for oral health boon or bane. Res Pharm Health Sci 2018;4(2):448-453.

18. Reid G, Jass J, Sebulsky MT, et al. Potential uses of probiotics in clinical practice. Clin Microbiol Rev 2003;16(4):658-672. DOI: 10.1128/ CMR.16.4.658-672.2003. 
19. Saxelin M, Tynkkynen S, Mattila-Sandholm T, et al. Probiotic and other functional microbes: from markets to mechanisms. Curr Opin Biotechnol 2005;16(2):204-211. DOI: 10.1016/j.copbio.2005.02.003.

20. Maukonen J, Mätto J, Suihko ML, et al. Intra-individual diversity and similarity of salivary and faecal microbiota. J Med Microbiol 2008;57(Pt 12):1560-1568. DOI: 10.1099/jmm.0.47352-0.

21. Crociani F, Biavati $B$, Alessandrini $A$, et al. Bifidobacterium inopinatum sp. Nov. And Bifidobacterium denticolens sp. Nov., two new species isolated from human dental caries. Int J Syst Bacteriol 1996;46(2): 564-571. DOI: 10.1099/00207713-46-2-564.

22. Beighton D, Gilbert SC, Clark D, et al. Isolation and identification of bifidobacteriaceae from human saliva. Appl Environ Microbiol 2008;74(20):6457-6460. DOI: 10.1128/AEM.00895-08.

23. Agarwal E, Bajaj P, Guruprasad CN, et al. Probiotics: a novel step towards oral health. AOSR 2011;1(2):108-115.

24. Geier MS, Butler RN, Howarth GS. Inflammatory bowel disease: current insights into pathogenesis and new therapeutic options; probiotics, prebiotics and synbiotics. Int J Food Microbiol 2007;115:1-11. DOI: 10.1016/j.ijfoodmicro.2006.10.006.

25. Roy D. Technological aspects related to the use of bifidobacteria in dairy products. Lait 2005;85:39-56. DOI: 10.1051/lait:2004026.

26. Shah NP. Functional cultures and health benefits. Int Dairy J 2007;17:1262-1277. DOI: 10.1016/j.idairyj.2007.01.014.
27. Haukioja A. Probiotics \& oral health. Euro J Dent 2010;4(3):348-355. DOI: 10.1055/s-0039-1697851.

28. Persson S, Edlund MB, Claesson R. The formation of hydrogen sulfide and methyl mercaptan by oral bacteria. Oral Microbiol Immunol 1990;5(4):195-201. DOI: 10.1111/j.1399-302X.1990.tb00645.x.

29. Kazor CE, Mitchell PM, Lee AM, et al. Diversity of bacterial populations on the tongue dorsa of patients with halitosis \& healthy patients. J Clin Microbiol 2003;41(2):558-565. DOI: 10.1128/jcm.41.2.558-563.2003.

30. Burton JP, Chiclott CN, Tagg JR. The rationale \& potential for the reduction of oral maladour using streptococcus salivarius probiotics. Oral diseases. 2005;11(Suppl 1):29-31. DOI: 10.1111/j.16010825.2005.01084.x.

31. Suzuki N, Yoneda M, Tanake K, et al. Lactobacillus salivarius WB21containing tablets for the treatment of oral malodor: a double-blind, randomized, placebo-controlled. Oral SurgOral Med Oral Pathol Oral Radiol 2014;117(4):462-470. DOI: 10.1016/j.00oo.2013.12.400.

32. Caglar E, Kargul B, Tanboga I. Bacteriotherapy and probiotics' role on oral health. Oral Dis 2005;11(3):131-137. DOI: 10.1111/j.16010825.2005.01109.x.

33. Kang M-S, Kim B-G, Chung J, et al. Inhibitory effect of Weissella cibaria isolates on the production of volatile sulphur compounds. J Clin Periodontol 2006;33(3):226-232. DOI: 10.1111/j.1600051X.2006.00893.x. 